\title{
Alfabetización visual de docentes de arte en formación en la Facultad de Bellas Artes (UCM) a través de representaciones visuales de su propio concepto de arte
}

\section{Resumen}

En este texto nos acercaremos a la alfabetización visual de quienes, formándose en bellas artes, quieren dedicarse a la docencia, y la importancia de esta en estos profesionales, con la intención de lograr los siguientes objetivos: 1) Medir la presencia de la alfabetización visual en las titulaciones. 2) Evaluar la alfabetización visual de estudiantes a través de su capacidad de representar un concepto abstracto mediante imágenes. 3) Indagar acerca del concepto de arte que tiene el alumnado y cuál eligen para transmitir.

Para ello, partimos de la premisa de que este alumnado debería ser experto en alfabetización visual, por el manejo que del lenguaje visual hacen como creadores y por el tipo de pensamiento (visual - espacial) que presuponemos predomina en ellos; revisamos el concepto de pensamiento visual y los de metáfora visual y pictograma.

En nuestro estudio de campo, y dentro del desarrollo de actividades sobre el tema, recogemos 25 metáforas visuales y 167 pictogramas realizados por el alumnado de diferentes titulaciones en los que se representa el concepto arte. Estos ejercicios son analizados tanto desde el punto de vista formal y de adecuación al lenguaje utilizado como desde su contenido, para medir la alfabetización visual y conocer el concepto de arte que pueden transmitir con ellos.

Los resultados nos muestran que la alfabetización visual no aparece en los documentos que describen las titulaciones, aunque sí conceptos relacionados (lenguaje visual, comunicación visual,...), pero hay asignaturas en los grados en bellas artes y en diseño que incluyen contenido relacionado. En cuanto a la realización de metáforas y pictogramas, la mayor parte del alumnado lo ha hecho satisfactoriamente, transmitiendo un concepto de arte muy relacionado con lo manual (aunque también con lo mental) y con el pincel y/o la paleta como imágenes clave para su representación.
Pedro Javier Albar Mansoa

Doctor en Bellas Artes.

Profesor, Universidad Complutense de Madrid, Madrid, España.

Correo electrónico: pjalbar@ucm.es

๑ orcid.org/0000-0002-4427-1780

Google Scholar

Noelia Antúnez del Cerro

Doctora en Bellas Artes.

Profesora, Universidad Complutense de Madrid, Madrid, España.

Correo electrónico: nantunez@ucm.es (1) orcid.org/0000-0003-4561-2572

Google Scholar

Recibido: marzo 17 de 2021 Aprobado: junio 23 de 202

Palabras clave: alfabetización visual, pensamiento visual, pictograma, metáfora visual, arte, facultad bellas artes. 


\section{Visual literacy of training Art professors in the Faculty of Fine Arts (UCM) through visual representations of their own concept of Art}

\begin{abstract}
An approach to the visual literacy of those who, being trained in Fine Arts, want to dedicate themselves to teaching, and the importance it has for these professionals is presented in this text with the intention of achieving the following objectives: 1) To measure the presence of visual literacy in Arts University Programs; 2) To assess the visual literacy of students through their ability to represent an abstract concept through images; 3) To inquire about the concept of Art that students have and which one they choose to transmit.
\end{abstract}

To do this, everything started from the premise that these students should be experts in visual literacy, due to their handling of visual language as creators and to the type of thinking (visual - spatial) that is assumed to predominate in them. The concept of visual thinking and those of visual metaphor and pictogram were reviewed.

In this field of study and within the development of activities on the subject, 25 visual metaphors and 167 pictograms made by students of different University Programs, in which Art is represented as a concept, were collected. These exercises are analyzed both from the formal point of view and from adaptation to the language used, as well as from its content to measure visual literacy and to know the concept of Art that can be transmitted with them.

The results show that visual literacy does not appear in the documents that describe the University Programs, although related concepts (visual language, visual communication...) do appear, but there are subjects in the Fine Arts and Design Programs that include related content. Regarding the realization of metaphors and pictograms, most of the students have done it satisfactorily transmitting a concept of Art closely related to the handmade (but also to the mental) and with the brush and/or the palette as key images for their representation.
Key words:

visual literacy, visual thinking, pictogram, visual metaphor, Art, Fine Arts college. 


\section{Introducción y justificación}

Este trabajo parte de la alfabetización visual, el concepto arte y la capacidad que tienen quienes estudian en la Facultad de Bellas Artes de la Universidad Complutense de Madrid (UCM) para interpretar y comunicar con imágenes, de forma esquemática (metáforas visuales y pictogramas), ideas y conceptos, con el propósito de inducir y promover en el alumnado el desarrollo de estas habilidades de expresión visual. El uso de estos modelos visuales ayuda a comunicar relaciones complejas (Garcés, 2020) de manera eficiente, funcionan como memoria externa que ayuda a compensar la capacidad limitada de la memoria de trabajo a corto plazo y favorecen la comprensión de relaciones complejas de información de forma eficaz (Worren et al., 2002).

Pensamos que los alumnos de la Facultad de Bellas Artes, más cuando al estar asistiendo a asignaturas del área de Formación Artística tienen un interés por la docencia, deberían automatizar estos procesos, porque el codificar y descodificar mensajes de este tipo los llevará a la progresiva adquisición de una amplia alfabetización visual y, por ende, una mayor cultura visual ${ }^{1}$, lo que es muy importante para poder transmitirlo en su futura docencia o creación artística (Amador-Baquiro, 2021). Para ello, planteamos diferentes ejercicios en relación con la metáfora visual y los pictogramas, como fórmula para promover esta automatización y, para esta investigación, hemos decidido centrarnos en aquellos casos en los que han tenido que representar un concepto clave en su posible futuro como docentes: arte. El poner el foco en este concepto y no en otro, parte de la preocupación devenida de comprobar que, en muchas ocasiones, no tienen herramientas para dar una definición verbal de un concepto que, por otro lado, deberían poder explicar tanto por ser artistas como por ser docentes (Antúnez del Cerro, 2005).

'Podemos definir cultura visual no solo en el sentido de Mirzoeff (2003) como la relación que se establece entre los espectadores y las imágenes, sino también como el conjunto de imágenes que pertenecen a la cultura de un individuo. 
Por lo tanto, nos proponemos comprobar la destreza en el uso de diferentes estrategias y técnicas que tienen los alumnos en estos métodos de composición creativa. Además, mediante su análisis, pretendemos entender el uso de la expresión y comprensión visual del alumnado de la Facultad de Bellas Artes, al igual que el concepto de arte que son capaces de transmitir de forma visual.

Con esto no pretendemos dar soluciones globales, pensamos que la clave es implementar diferentes métodos que favorecen el cambio mediante procesos que implican otra forma de aprender a observar, pensar y organizar, que favorecen otra cultura del pensamiento, ayudan a esquematizar, sintetizar, estructurar y relacionar contenidos y, por supuesto, implican saber desarrollar modelos de intercambio y comunicación de conocimiento. Así plantamos una semilla que vaya germinando y facilite un cambio hacia un mejor pensamiento visual imaginativo, vinculando el conocimiento y el desarrollo visual cognitivo que complemente al avance visual/artístico del alumnado durante sus estudios.

\section{Objetivos}

- Analizar las titulaciones de la Facultad de Bellas Artes de la UCM para medir la presencia de la alfabetización visual en ellas.

- Evaluar la alfabetización visual de estudiantes de la Facultad de Bellas Artes de la UCM a través de su capacidad de representar un concepto abstracto mediante imágenes, en este caso el de arte.

- Indagar acerca del concepto de arte que tiene el alumnado de la Facultad de Bellas Artes de la UCM y cuál eligen para transmitir. 


\section{Metodología}

La investigación desarrollada podría definirse de la siguiente forma:

- Teórica, ya que no buscamos una aplicación práctica directa de los resultados de la misma, más allá de ampliar nuestro conocimiento sobre el alumnado y su formación en cuanto a los temas que nos atañen: su alfabetización visual y el concepto de arte que manejan y trasladan.

- Exploratoria, debido a que este estudio no es más que un primer acercamiento a la cuestión, no tiene intención de profundizar por lo que no se han tenido en cuenta todas las posibles ramificaciones del mismo.

- Inductiva, ya que, en nuestro deseo de conocer al estudiantado desde el punto de vista de su alfabetización visual, pretendemos que el conocimiento particular de aquellos que han participado en la investigación nos permita generar una teoría aplicable al resto de sus iguales.

\section{Contexto de investigación}

Esta investigación se ha desarrollado partiendo de datos obtenidos del análisis de documentos sobre las titulaciones impartidas en la Facultad de Bellas Artes de la UCM y de la docencia implementada entre los cursos 2014/15 y 2020/21 en las siguientes asignaturas y con la siguiente participación:

- Bases didácticas para la educación artística (asignatura obligatoria del Grado en Bellas Artes), curso 2020/21 con 15 estudiantes.

- Educación artística como recurso en contextos de salud y bienestar (asignatura obligatoria del Máster en Educación Artística en Instituciones Sociales y Culturales - MEDART), curso 2020/21 con 10 estudiantes.

- Procesos y métodos del diseño (asignatura optativa del Máster de Formación del Profesorado de Educación Secundaria, Bachillerato, FP y Enseñanza de Idiomas - MFPS), cursos entre 2014/15 y 2020/21 con 167 estudiantes. 


\section{Procedimiento de recogida de datos}

Para alcanzar el primer objetivo, relacionado con la presencia de la alfabetización visual en los estudios que se imparten en la Facultad de Bellas Artes de la UCM, nos hemos fijado en las siguientes titulaciones:

- Grado en Bellas Artes.

- Grado en Diseño.

- Grado en Conservación y Restauración del Patrimonio Cultural.

- Máster Universitario en Investigación en Arte y Creación.

- Máster Universitario en Diseño.

- Máster Universitario en Conservación del Patrimonio Cultural.

- Máster Universitario en Educación Artística en Instituciones Sociales y Culturales.

- Máster Universitario en Formación del Profesorado de ESO y Bachillerato, FP y Enseñanzas de Idiomas.

Con esta intención, hemos analizado los documentos que marcan las características principales de las diferentes titulaciones que se imparten en la misma:

- Presentación de estas en sus respectivos sitios web, incluyendo definición, competencias, objetivos y contenidos.

- Dípticos creados por la universidad para dar a conocer los diferentes grados y másteres.

- Listado de las asignaturas que componen cada estudio, y las fichas didácticas de muchas de ellas. 
Buscando alcanzar los otros dos objetivos (evaluar la alfabetización visual e indagar en el concepto de arte que manejan los estudiantes), hemos recogido datos de tres asignaturas diferentes correspondientes a tres titulaciones distintas, todas ellas impartidas en la misma facultad. Estos provienen de sendos ejercicios que se han planteado dentro de la programación de las mismas, no como resultado de cuestionarios hechos ex profeso para la investigación. En estos ejercicios se les ha pedido representar visualmente el concepto arte bajo ciertas premisas relacionadas con cada asignatura y en forma de metáfora visual o pictograma, por lo que consideramos necesario explicar brevemente el contexto de realización de las prácticas de las cuales hemos obtenido los resultados.

\section{Bases didácticas para la educación artística}

Esta es una asignatura obligatoria para estudiantes del tercer curso del Grado en Bellas Artes, en la que se les introduce en competencias básicas para diseñar, implementar y evaluar proyectos educativos en diferentes contextos de la educación artística en educación no formal. Aunque este alumnado ya posee una formación artística obtenida en cursos anteriores, carecen de medios para transmitir estos conocimientos dentro de la docencia, por lo que para adquirir estas competencias introducimos, entre otros, recursos relacionados con la alfabetización y el pensamiento visual.

En la propuesta Metáforas visuales de conceptos verbales abstractos, transforman un icono (que ya diseñaron en la actividad anterior) y lo convierten en ideograma para dotarlo de ideas y significados, representando una serie de ideas o conceptos abstractos, dibujados a mano alzada sobre papel, entre los que se encuentra el de arte. 
El objetivo es que el receptor detecte las ideas representadas para conectarlas y concretarlas de forma global, interviniendo aquí también su bagaje cultural y su capacidad de lectura visual (Ferruzca et al., 2015). La metáfora visual, tal como la entendemos en este contexto, va a ser un recurso que permite combinar uno o varios ideogramas a un concepto verbal y hacer comprensible una idea de la forma más rápida y sencilla posible (De Salazar-Muñoz y Albar-Mansoa, 2016). Esta codificación gráfica por parte del emisor, que debe mantener sencillez de ejecución, rapidez de asimilación y comprensión, que son la clave de una buena metáfora visual, es lo que les resulta difícil de conseguir.

\section{Educación artística como recurso en contextos de salud y bienestar}

El alumnado de este máster, en su mayoría (60\%), suele tener formación en bellas artes, un 35\% proceden de historia del arte y un 5\% de perfiles afines (diseño, arquitectura, restauración,...).

Las prácticas que se introducen con el objetivo de favorecer a su alfabetización visual y a su capacidad de alfabetizar visualmente en el futuro, se incorporan en una unidad didáctica avanzada dentro de la asignatura, cuando empiezan a tener más claras sus predilecciones personales. Por ello, es el momento ideal para la realización de mapas de relación con conceptos y metáforas visuales para organizar sus intereses. Esta práctica comienza con la presentación teórica sobre alfabetización visual, pensamiento visual, gestión de la carga cognitiva, desarrollo de la capacidad de síntesis, iconos e iconicidad, metáforas visuales, mapas mentales y mapas conceptuales con diferentes ejemplos (Kreger-Silverman, 2005). Para la práctica, se hace especial énfasis en realizar la metáfora visual del concepto relacionado (en algunos casos el de arte), se les da la opción de realizar un mapa mental o mapa conceptual con conceptos de su interés dentro del máster y con relación a la asignatura, detectando beneficios en presentaciones y trabajos fin de máster. 


\section{Procesos y métodos del diseño}

Quienes cursan la asignatura Procesos y métodos del diseño tienen, en su mayoría, formación en bellas artes, por lo que, aunque son conocedores de los elementos básicos del lenguaje visual (y por lo tanto deberían tener una alta alfabetización visual) antes de empezar la práctica que nos interesa, no lo son de su aplicación en el diseño. Por ello, la asignatura comienza con dos ejercicios que permiten valorar su capacidad de enfrentarse a un nuevo uso del lenguaje visual aplicándolo al diseño de una ficha de clase personal y unos pictogramas.

Antes de realizar los pictogramas, se revisan tanto su definición como las características que deben tener, las diferencias y relaciones entre pictogramas y señales, la historia de la creación de algunos ejemplos o su aplicación en el arte, el diseño, la cultura visual y la educación secundaria (Antúnez del Cerro, 2014). La propuesta práctica es la de generar tres pictogramas, en este caso sobre los conceptos de arte, diseño y artesanía, partiendo de las características expuestas en la presentación, y que deberían servir para identificar estas tres disciplinas en un espacio como una escuela de arte, por ejemplo, en carteles que marcarán los espacios destinados a cada una de ellas.

A la hora de realizar sus pictogramas, se propone que realicen la versión final recortando las formas en cartulina negra o blanca (que colocarán sobre una cartulina de color contrario) para ayudarles a eliminar detalles innecesarios que, si realizan su ejercicio dibujando, suelen ser más difíciles de evitar. 


\section{Fundamentos teóricos}

\section{Pensamiento visual}

Sería lógico pensar que quienes estudian en una Facultad de Bellas Artes tienen una gran alfabetización visual ya que deberían, igualmente, tener un pensamiento visual muy desarrollado. Pero el pensamiento visual y la alfabetización visual no deberían ser un patrimonio exclusivo de quienes se dedican al ámbito de las artes visuales, ya que se aplica en muchos campos del saber; ejercitarlo favorece la creatividad, la imaginación y el pensamiento crítico, facilita la comprensión de conceptos y ayuda al aprendizaje de forma didáctica. Además, como decía Arnheim (1969), "percibir y pensar son actos que se encuentran indivisiblemente entremezclados" (p. 11) y es, a través de la vista, como percibimos y aprendemos la mayoría de la información:

\footnotetext{
Somos animales visuales: el 90\% de toda la información que llega a nuestro cerebro es de tipo visual y procesamos las imágenes hasta 60.000 veces más rápido que cualquier texto. Afirman los estudios que retenemos un $10 \%$ de la información que oímos, un $20 \%$ de la que leemos, pero hasta un $80 \%$ de la que vemos. Otro ejemplo: el $90 \%$ de todo el tráfico de internet son vídeos. Esta configuración innata e inconsciente de nuestro cerebro para procesar los estímulos visuales, a la que denominamos pensamiento visual o 'visual thinking', puede ser desarrollada y aprovechada para descubrir, generar, desarrollar, manipular, relacionar y compartir ideas de un modo rápido e intuitivo. (Cantón, 2017, p. 3)
}

Pero, aunque esta importancia de la información visual es común a la mayoría de los seres humanos, los estudios de Linda Kreger Silverman (2005) sobre el desarrollo infantil, muestran que cerca del 30\% de las personas tiene un fuerte pensamiento visual/espacial, el $45 \%$ utiliza de forma equilibrada tanto el pensamiento visual/espacial como el pensamiento en forma de palabras y el 25\% emplea únicamente el pensamiento en palabras. 
Nel Ojemann (1987), profundizando sobre el peso de lo visual en el desarrollo humano, describió el pensamiento visual como "una forma de pensamiento que todo el mundo utiliza mientras es joven" (s.p.). Para Ojemann, el pensar en imágenes y acciones es una manera de interactuar con la realidad que se va perdiendo cerca del quinto y sexto año de vida, coincidiendo con el cambio de la educación infantil a educación primaria, ya que se va transformando a favor del pensamiento verbal. Sin embargo, según la autora, el pensador en imágenes no abandona el método y lo sigue utilizando y, creemos, que en el alumnado de artes se puede dar más esta tipología de pensamiento. "A medida que se incorporen más elementos visuales para lograr un equilibrio óptimo entre las señales verbales y visuales en la educación, se fomentará la interdependencia entre los dos modos de pensamiento" (Kellner, 1998, en Stokes, 2002, p. 11).

Podríamos decir que los estudiantes con capacidades visuales-espaciales piensan en imágenes más que en palabras, aprenden mejor visualmente $y$, por lo tanto, su organización cerebral es diferente de quienes se podrían considerar secuenciales-auditivos. Quienes destacan por sus capacidades visuales-espaciales, además, suelen tener una gran imaginación, a menudo desordenada, forman fuertes imágenes mentales, son capaces de establecerlas en movimiento, creando sus propias películas mentales mientras leen o escuchan y se relacionan bien con las capacidades espaciales tanto de forma bidimensional como de forma tridimensional. También aprenden de forma integral, primero necesitan ver de manera general antes de aprender de los detalles, pero no son secuenciales, no aprenden paso a paso. Llegan a soluciones correctas sin un patrón establecido por lo cual les cuesta mostrar su trabajo. Aprenden conceptos difíciles o complejos con facilidad y tienen buena capacidad de síntesis de la información. 


\section{Metáfora visual}

La metáfora tiene una bibliografía muy densa, con múltiples referencias, y más si el estudio de la metáfora tiene un carácter multidisciplinar y con una gran variedad de enfoques (Nubiola, 2000). Su inclusión dentro de nuestros programas docentes tiene que ver con su alta capacidad de facilitar la comunicación y el aprendizaje, cosa que ya mencionaba Aristóteles al considerarla como herramienta de cognición (Eppler y Burkhard, 2007) y con las relaciones entre lo gráfico y el desarrollo cognitivo (Spencer et al., 1989).

Pero, nosotros, nos centramos en la metáfora visual y no en las metáforas articuladas mediante lenguaje verbal $y$, en especial, lo haremos con la que generan los ideogramas ${ }^{2}$ y los pictogramas, tanto de forma individual (ver Figura 1) como por combinación de varios. Dentro de este tipo de mensaje visual, partimos de la idea de que si una metáfora visual (en retórica visual) tiene un significado más abstracto/poético, de sustitución de un elemento por otro por relación de semejanza, en este contexto y con este tipo de símbolos icónicos, tiene justo la función contraria: dotarla de un mayor significado y del mayor contenido de información posibles (Martínez-Vérez y Albar, 2019), por lo que hablamos de lo que hemos denominado metáfora visual cognitiva (ver Figura 2).

\footnotetext{
${ }^{2}$ En este punto, definimos ideograma, sobre todo para diferenciarlo del pictograma. El ideograma, según la segunda acepción del diccionario de la Real Academia de la Lengua Española (DRAE), es: "Imagen convencional o símbolo que representa un ser o una idea, pero no palabras o frases fijas que los signifiquen". Si los ideogramas representan palabras, estos podrían clasificarse como iconos, en el contexto que lo utilizamos, pueden estar relacionados con conceptos verbales a modo de anclaje contextual, pudiéndose combinar varios ideogramas interactuando con significantes verbales para multiplicar sus significados. La tercera acepción que nos interesa del ideograma es la siguiente: "formar en la mente una imagen visual de un concepto abstracto" (DRAE).
} 
Albar, P. J. y Antúnez del Cerro, N. / Alfabetización visual de docentes de arte en formación en la Facultad de Bellas Artes (UCM) a través de representaciones visuales de su propio concepto de arte

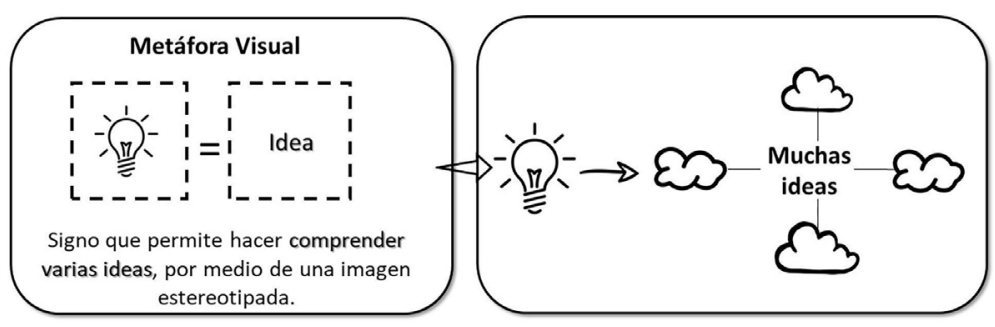

Figura 1. Metáfora visual mediante signo/ideograma que puede hacer comprender varias ideas. Fuente: Albar (2021)

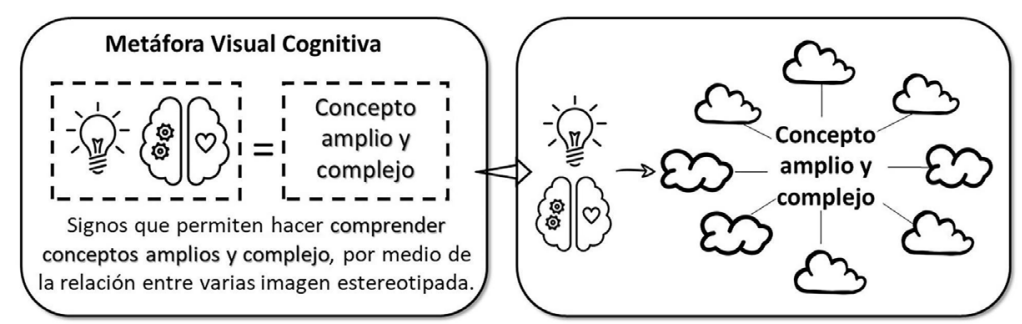

Figura 2. Metáfora visual cognitiva mediante signos/ideogramas que puede hacer comprender conceptos amplios y complejos. Fuente: Albar (2021)

A la metáfora visual que tratamos, asociada a conceptos más abstractos que en algunos casos son más difíciles de comprender con un solo pictograma/ icono, [como postula Lakoff (1993), entre otros autores], podríamos denominar como metáfora compleja ya que está formada "a partir de las metáforas primarias y formas de conocimiento común, tales como los modelos culturales o los conocimientos y creencias ampliamente compartidos en una cultura. Los conceptos se construyen creando metáforas complejas a partir de metáforas primarias" (Aguilar, 2012, p. 55). Así, el proceso cognitivo que se realiza dentro de este proceso comunicativo viene de una proyección mental convertida en una representación visual, a través de metáforas como origen, 
y el posterior análisis de los elementos representados, lo que implicaría otro proceso mental en el destinatario del mensaje (Cuenca y Hilferty, 1999).

Con la articulación de ideogramas gráficos generamos la metáfora visual ya que estos pueden dar lugar a múltiples imágenes perceptuales y por tanto a múltiples significados (Martín-Hernández, 2020). La combinación de estos ideogramas puede transformarse en la memoria de cada persona según el conocimiento previo y el contexto en el que se encuentre la metáfora, en algunos casos junto a un concepto verbal o una palabra clave. Dependiendo del contexto, una misma metáfora visual puede tener diferentes significados, ya que serán interpretadas por la mente perceptora "mediante la activación de operaciones cognitivas diferentes" (Magariños, 2001 p. 301), pero en la dirección de un significado similar.

Como dice Aladro (2007), "nuestra mente se sirve de los iconos y las representaciones para disminuir la carga informativa" (p. 53) pero no la capacidad cognitiva que podemos relacionar. La metáfora visual cognitiva nos va a facilitar la comprensión de algo nuevo o algo conocido, utilizando elementos que nos facilitan la comprensión de un tema a otra dimensión de conocimiento.

Como Worren et al. (2002) han señalado, las metáforas también pueden mejorar la memorización y la coordinación en grupos. Las metáforas visuales utilizadas para la transferencia de conocimientos o la creación pueden ser objetos o fenómenos naturales (...) u objetos artificiales, hechos por el hombre (...), actividades (...), o conceptos (...). Su característica principal es que organizan la información de manera significativa. Al hacerlo, cumplen una doble función: en primer lugar, colocan la información gráficamente para organizarla y estructurarla. En segundo lugar, transmiten una percepción implícita sobre la información representada a través de las características clave (o asociaciones) de la metáfora que se emplea. (Eppler y Burkhard, 2007, p. 117) 
Como hemos mencionado, tratamos la metáfora como un proceso mental en el que organizamos la información gráfica y la relacionamos con nuestro conocimiento, como recurso cognitivo de comunicación de nuestro pensamiento (Ortiz, 2011) y que puede ser particular de cada persona. Estas imágenes icónicas que percibimos y se proyectan en la mente, con cierto grado de abstracción, facilitan la comprensión ya que producen la adquisición de la información en un sentido concreto e indican el significado también en un sentido (Aladro, 2007). Su uso en el ámbito educativo es también interesante puesto que:

Pensar con metáforas coloca a la mente en búsqueda de semejanzas y paralelismos. También activa el pensamiento de la proyección y de la ampliación de los límites entre lo disímil. También induce al cambio porque toda proyección es en realidad una búsqueda de elementos nuevos o de planos nuevos de aplicación de pensamiento. (Aladro, 2007, p. 55)

Autores como Fuster (1995) o Magariños (2001), denominan atractor al conjunto de formas (en este caso ideogramas) que conforman una imagen mental con cierta constancia que produce una fijación o permanencia en la memoria visual, permitiendo al receptor identificar la imagen visual propuesta, reconfigurando e identificando sus significados por correspondencia.

Las metáforas visuales pueden interactuar de forma estática o dinámica (gestos de personajes, movimiento de los elementos) potenciando los significados, como dice Hoffman (1998, p. 104, citado en Magariños, 2001): “Para construir objetos, se necesita construir partes. Pero también se necesita (...) ensamblar esas partes en relaciones espaciales coherentes" (p. 306). Así, la interacción visual icónica puede estar compuesta por diferentes ideogramas y su lectura será en conjunto, con un significado global y, en el caso de utilizar el texto, este funcionará como anclaje de un significado más complejo o profundo, variando según la educación, la cultura, profesión y áreas de conocimiento del receptor. 
Como conclusión, podríamos decir que, para que una metáfora visual sea tal y funcione como recurso educativo al cumplir con las características descritas, debería cumplir con las siguientes premisas:

- Ser de ejecución sencilla, es decir, partir de ideogramas que representen de forma esquemática y globalmente un concepto.

- Debe ser comprendida de forma rápida y clara, para lo que debe favorecer una lectura rápida (lo que está relacionado con la sencillez de ejecución), e inequívoca en lo esencial, para lo que es necesaria una gran alfabetización visual de quien la cree, ya que hay que tener en cuenta la cultura visual de posibles receptores.

- Puede contener texto como elemento de apoyo a la imagen o las imágenes, que favorezca la comprensión del conjunto o de algunos conceptos que, mediante ideogramas puramente esquemáticos, costaría descifrar de forma rápida y clara.

\section{Pictogramas}

Partiendo de su etimología (picto que proviene del latín pinctus — pintado_y grama del griego үрá $\mu \mu$ - escrito o trazado-), podríamos definir a los pictogramas como una imagen que representa una palabra. Esta representación tendría un cariz más icónico y, por lo tanto, respetaría una semejanza visual con lo representado, que esquemático o abstracto (lo que caracterizaría a los ideogramas), ya que representaría un objeto o figura real y no una idea o concepto abstracto (pensamientovisual.es, s.f.; Hall, 2007).

La representación en los pictogramas debe de ser clara, ya que este tipo de imagen figurativa (en el sentido de mantener cierta iconicidad) debe de ser reconocible, aunque sea con la interpretación de mínimos elementos gráficos. Asimismo, esta imagen debe de tener, tanto para el creador-emisor como para 
el intérprete-receptor, la capacidad de configurar significados almacenados en la memoria visual, un registro mnemónico que irá asociado al conocimiento del concepto-contexto.

En cuanto al pictograma como mensaje visual, para que sea "un signo de otra cosa, debe tener un rango relativamente bajo en la escala de prototipicidad que se aplica a las cosas de la vida" (Sonesson 1997, p. 34). Su realización debería ser relativamente sencilla y cualquier persona, independientemente de su nivel de alfabetización visual o destreza manual, podría generar un alfabeto visual de pictogramas, diseñando iconos simples de cualquier objeto ya que todos tenemos un esquema mental de cómo es ese objeto y, en cuanto a la destreza, cada persona puede dibujar, como mínimo, con las características de la etapa esquemática del desarrollo del dibujo infantil, según postulan Lowenfeld y Brittain (1972).

En el caso de los pictogramas, al igual que en cualquier acto de comunicación, hay que tener en cuenta que estos pueden adquirir un significado diferente dependiendo del contexto en el que se utilicen, y es en el contexto cuando el pictograma entra en relación y adquiere su potencial (Sonesson, 1994) (ver Figuras 3 y 4 ).

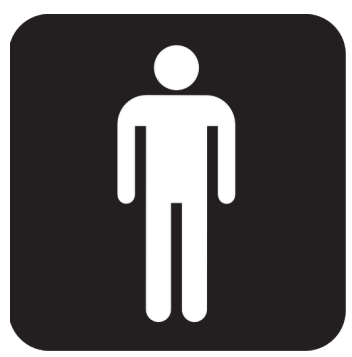

Figura 3. Pictograma NPS de baño para hombres. Este pictograma de "hombre", en contexto, podemos interpretarlo como el que identifica el baño para hombres. Fuente: johnny_automatic (2008). 


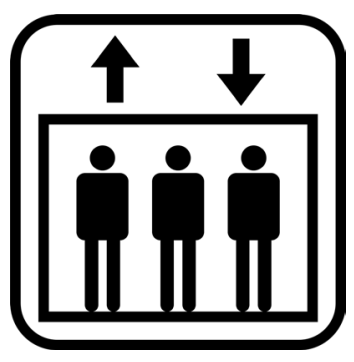

Figura 4. Pictograma de ascensor. Aquí los pictogramas de "hombre" utilizados no representan solo a los seres humanos de género masculino, sino a todos ellos (hombres y mujeres) ya que se entiende que el ascensor es de uso común. Fuente: ColdShine (2005).

En resumen, para que un pictograma sea tal, debería cumplir las siguientes características (Antúnez del Cerro, 2014):

- Debe ser decodificado de forma rápida y sencilla, incluso desde una distancia grande como, por ejemplo, en una carretera.

- Debe ser abstracto, esquemático y no perderse en los detalles, es decir, debe representar al concepto general de lo representado y no a un ejemplo particular.

- Debe tener una vocación universal, para que pueda ser entendido por personas de diferentes edades, formaciones, culturas,... sin inducir a errores de interpretación.

- Debería de poder ser comprendido sin texto, ya que si necesitara texto para ser explicado no sería un pictograma. 


\section{Análisis de resultados}

\section{Alfabetización visual en las titulaciones de la Facultad de Bellas Artes}

En esta investigación partimos de la creencia de que quienes estudian en la Facultad de Bellas Artes deberían tener una gran cultura visual y una buena alfabetización. Para hacer una aproximación al conocimiento que sobre el tema de la alfabetización visual adquiere el alumnado de esta facultad de forma explícita (obviando el que se puede obtener por la adquisición de competencias afines, del trabajo personal, el desarrollo de obra o el conocimiento de artistas), como comentamos, hemos revisado los documentos en los que se definen las titulaciones que se imparten en dicho centro. En todos estos documentos, comenzamos por la búsqueda de las que consideramos palabras clave para definir esta área de conocimiento como: visual, lenguaje, comunicación y alfabetización. Ninguna de estas palabras apareció en las presentaciones, dípticos o listados de asignaturas de la mayoría de las titulaciones, siendo las dos únicas que las incluyen en competencias, contenidos u objetivos el Grado en Diseño y el Máster Universitario en Investigación en Arte y Creación.

En el Grado en Diseño encontramos un objetivo que incluye el término "visual", ya que se pretende que quienes lo cursen tengan la capacidad de intervenir en la cultura material y visual del ser humano ("Competencias del Grado en Diseño", Facultad de Bellas Artes, s.f.). Además, este grado incluye un itinerario en Diseño Gráfico, cuyo propósito es el de ampliar "su preparación para el diseño aplicado a la comunicación visual mediante el dominio de disciplinas y técnicas específicas" ("Estructura del plan de estudios del Grado en Diseño", Facultad de Bellas Artes, s.f.).

Asimismo, en el díptico de dicha titulación se incluye, dentro del listado de los conocimientos que se pueden adquirir en dicha titulación, "Lenguajes 
y herramientas gráficas para modelizar, simular y resolver problemas en el ámbito del diseño" (Departamento de Estudios e Imagen Corporativa, 2021); explicitando la necesaria alfabetización visual de quienes estudian este grado.

Dentro del Máster Universitario en Investigación en Arte y Creación, estos términos se incluyen en varias ocasiones. En primer lugar, existe un Módulo Fundamental de asignaturas Ilamado de Lenguajes Artísticos, en el que se agrupan asignaturas tanto obligatorias como optativas ("Estructura del Máster Universitario en Investigación en Arte y Creación", Facultad de Bellas Artes, s.f.), lo que explicita, en cierto modo, la necesidad del desarrollo de un lenguaje artístico (en nuestro ámbito visual) para quienes lo cursen. Asimismo, uno de sus objetivos es:

Desarrollar la formación intelectual y la capacidad crítica del/a estudiante, desde el ámbito del arte y la cultura visual, como futuro creativo en el ámbito de la imagen y responsabilizar su producción a fin de entender el contexto cultural para generar iniciativa y dinamizar el entorno. ("Competencias del Máster Universitario en Investigación en Arte y Creación", Facultad de Bellas Artes, s.f.)

Además, existen tres competencias que incluyen el término "visual", al mencionar la vinculación del arte con la teoría visual contemporánea, o la relación del dibujo o la pintura con la cultura visual.

Con estos objetivos y competencias podemos ver cómo la intención es que su alumnado adquiera conocimientos sobre cultura, teoría o estudios visuales, así que, aunque en parte se acerca al elemento clave de esta investigación, no se menciona explícitamente el lenguaje visual o su adquisición (alfabetización visual).

Sin embargo y aunque no se mencionen las palabras clave analizadas (visual, lenguaje, comunicación y alfabetización) en el resto de las titulaciones, sí que hemos encontrado asignaturas que se ocupan de una forma explícita de estos conocimientos. 
- En el Grado en Bellas Artes nos encontramos con la asignatura Análisis de la forma que pretende desarrollar "un conocimiento sistematizado de los principios y leyes que determinan las distintas lecturas de las imágenes" (Cuevas, s.f., p.1) y entre cuyas competencias se incluye "C.E.6. Conocimiento del vocabulario, de los códigos, y de los conceptos inherentes al ámbito artístico. Conocer el lenguaje del arte" (Cuevas, s.f., p. 2).

- En el Grado en Diseño encontramos una asignatura denominada Elementos de la plástica, en la que se incluye de una forma más expresa lo relacionado con la alfabetización visual y su importancia en la comunicación al describirse como una asignatura que "estudia la sintaxis de la imagen; este conocimiento partirá del desarrollo de la capacidad crítica para reconocer el alfabeto visual hasta llegar a la puesta en práctica de dichos recursos en la creación de imágenes por parte del alumno" (Zurdo, s.f., p. 1).

- Dentro del resto de titulaciones encontramos otras asignaturas como Imagen pictórica en la cultura visual del Máster Universitario en Investigación en Arte y Creación, o las del Máster Universitario en Diseño llamadas Imagen visual y packaging, Visualización de datos y Animación y diseño para la producción audiovisual en las que se habla de identidad e imagen visual, información visual, cultura visual,... pero no de los elementos que forman parte de ese lenguaje y su uso.

\section{Capacidad del alumnado de transmitir conceptos de forma visual}

\section{Metáfora visual}

Al analizar las características de las metáforas con la intención de valorar la capacidad del alumnado para transmitir conceptos de forma visual, lo hemos hecho partiendo de las premisas que se dieron como necesarias para que estas estuvieran bien construidas. 
- Ser de ejecución sencilla. Son representaciones sencillas un $40 \%{ }^{3}$ de las metáforas, es decir, han comprendido la sencillez de la metáfora visual solicitada, sin perder su poder comunicativo y cognitivo. Un 60\% es de ejecución más compleja, algunas tienen que ver con el concepto de metáfora visual cognitiva, en ocasiones sobrecargadas de información y con falta de capacidad de síntesis.

- Debe ser decodificado de forma rápida y sencilla. En la mayoría de los casos (80\%) aparecen elementos fácilmente reconocibles por su grado de figuración en la representación, pero existe otro grupo (20\%) que no se puede interpretar formalmente de forma sencilla o son representaciones artísticas abstractas no figurativas.

- Puede contener texto. En un 28\% acompañan la metáfora visual con texto conceptual o palabras clave, como forma de apoyo a la metáfora visual y en las interpretaciones que derivan en representaciones relacionadas con una comprensión de la práctica relacionada con visual thinking, diagramas de infografías, mapas conceptuales y/o mentales.

Además, del cumplimiento o no de las premisas dadas sobre la correcta creación de una metáfora, queremos destacar los siguientes resultados en cuanto a la realización de las mismas:

- Nos encontramos dos casos curiosos que pensamos debemos mencionar $(8 \%)$ en los que esta se explica y justifica con texto, externo a la propia metáfora visual, para que la entendamos y comprendamos la utilización de los elementos representados, aun siendo esto algo que no se pedía como parte del ejercicio.

- Más que el arte, parecen haber representado el proceso creador. Representan los diferentes elementos que intervienen en el arte como la imaginación, 
la creatividad, los sentimientos, la expresividad; o las funciones del mismo (expresar, comunicar, enseñar,...) (36,4\%).

- Utilizan tanto texto (28\%) como elementos gráficos tales como flechas, círculos o formas que envuelven,... (44\%) que tienen que ver con conceptos de representación relacionados con prácticas anteriores (visual thinking, diagramas de infografías, mapas conceptuales y/o mentales).

\section{Pictogramas}

Igualmente, para analizar los pictogramas realizados por el estudiantado, evaluamos si estos poseen las características que se mencionan en la fundamentación teórica, con los siguientes resultados:

- Debe ser decodificado de forma rápida y sencilla. En la mayoría de los casos $\left(84,7 \%{ }^{4}\right)$ los pictogramas, independientemente del concepto representado y de la formación previa de los autores, representan objetos y acciones fácilmente identificables (Figura 3). Sin embargo, algunos de ellos (15,3\%) resultan imposibles o complicados de interpretar, normalmente porque los elementos representados no se reconocen (aunque se conozcan).

- Debe ser abstracto, esquemático y no perderse en los detalles. Salvo alguna pequeña salvedad en la que existe profusión de detalles (en torno a un $5 \%$ ), la mayoría de los pictogramas representan los elementos de forma esquemática.

- Debe tener una vocación universal. El conocimiento que muchos alumnos tienen como creadores en estos ámbitos, loes lleva a querer representar estos conceptos a través de herramientas u otras referencias que, si bien son conocidas por la mayoría de quienes se dedican a ello, no lo son para quienes no las manejan, por lo que en ocasiones no logran esa vocación universal. 
- Debería de poder ser comprendido sin texto. Esta última premisa ha sido cumplida por todos los estudiantes, ya que ninguno ha utilizado texto para representar los conceptos, aunque hayan utilizado signos tipográficos o letras para representar, por ejemplo, la acción de pensar o el concepto de tipografía (ver ejemplo en Figura 5).

- Además, podríamos decir que, en la línea de lo que expone McCloud (2008), se han mantenido alejados de una representación más realista, utilizando, en la mayoría de los casos, una codificación que tiene a la abstracción icónica.

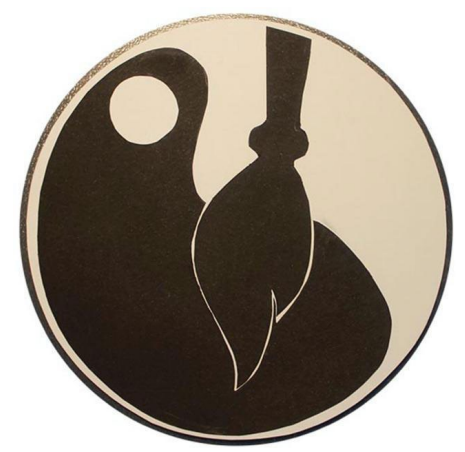

Figura 5. Pictograma para arte. Se puede observar cómo la autora ha cumplido, en un grado medio/alto con las características transmitidas para la realización correcta de un pictograma. Fuente: Goméz Manzaneque (2015).

\section{Concepto arte transmitido por el alumnado}

\section{Metáfora visual}

Aunque hay un gran porcentaje de estudiantes que recurren al carácter manual o físico del arte para representar el concepto $(81,8 \%)$, hay otra parte importante 
que destacan lo relacionado con el pensamiento creativo (54,5\%) o que, en lugar de reflejar lo que tiene que ver con la producción, ya sea la parte manual o la parte mental, prefieren hablar de las características del arte o sus funciones $(45,5 \%)$.

En cuanto a las disciplinas representadas, la que lo hace en la mayoría de los casos es la pintura $(77,3 \%)$ siendo representada en su mayor parte junto a otras disciplinas. La mayoría de las veces la pintura se representa a través de dos de sus herramientas básicas como lo son los pinceles y las paletas $(63,6 \%)$. (Ver ejemplos en Figura 6).
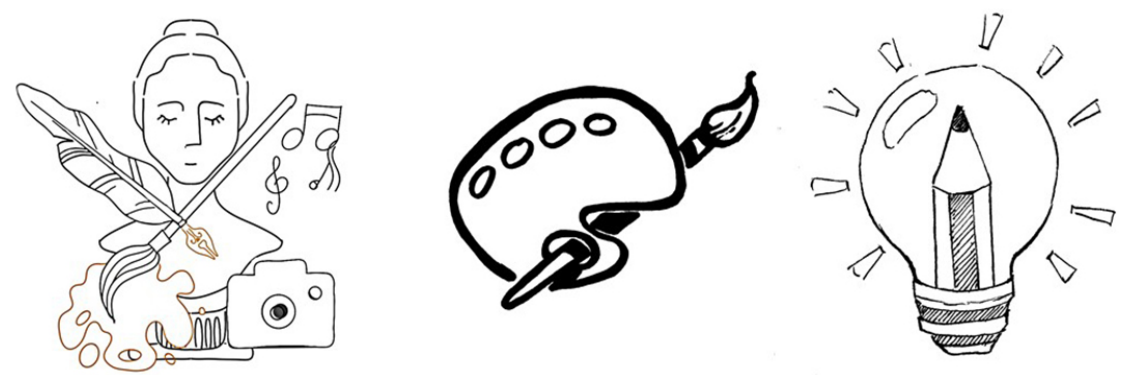

Figura 6. Metáforas visuales concepto Arte. Ejemplos de diversas representaciones. Fuente: Alba Rodríguez, Raúl Hernández y Antonio Puertas (2020).

\section{Pictogramas}

La mayor parte de los pictogramas que representan el arte incluyen en ellos elementos relacionados con la creación manual $(89,9 \%)$ ya que la mayoría representan herramientas, manos u objetos; frente a un 9,2\% que relaciona el arte con el pensamiento o las ideas, lo que se representa a través de bombillas, signos de interrogación o personas en posición de pensamiento. 
Destaca el que un $86,2 \%$ de los pictogramas utilizan la pintura para hablar de arte (ya sea sola o acompañada de otras disciplinas como - por orden de frecuencia - la escultura, la arquitectura, la música o el cine) representando pinceles (33,9\%), paletas $(36,7 \%)$ u obras concretas $(13,8 \%)$ como "El caballero de la mano en el pecho" (El Greco, entre 1578 y 1580), "La Gioconda" (Leonardo da Vinci, 1503-1519) o la "Victoria de Samotracia" (hacia el 190 a.C.); además de marcos o caballetes. (Ver ejemplo en Figura 7).

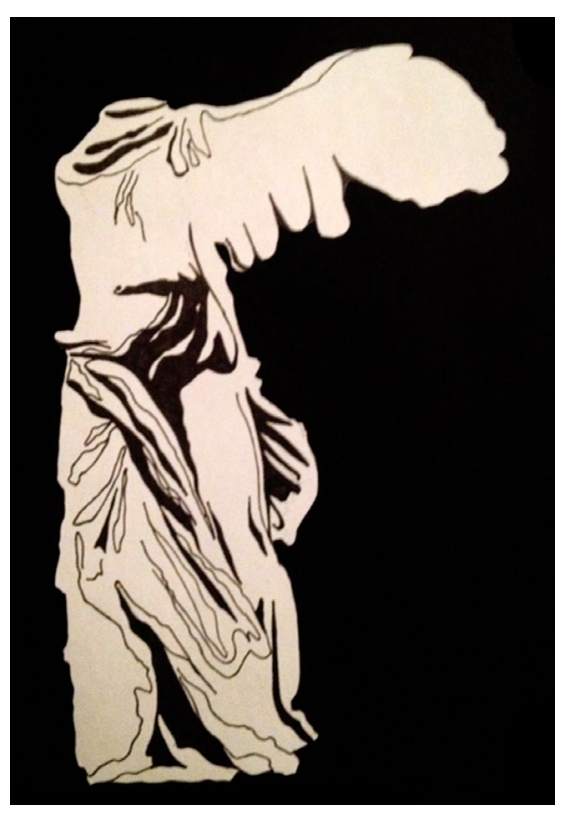

Figura 7. Pictograma de Arte. En este ejemplo podemos ver un ejemplo de elección de una obra concreta para representar el concepto arte.

Fuente: Álvarez Álvarez, A.M. (2014). 


\section{Conclusiones}

\section{Sobre la alfabetización visual}

Hemos visto que sería lógico pensar que el alumnado de Bellas Artes tiene modelos de aprendizaje más cercanos a capacidades visuales-espaciales, característica del desarrollo del pensamiento visual, con una herencia derivada de la educación formal cercana al enfoque auditivo y secuencial (KregerSilverman, 2005), por lo que deberían poseer una alta alfabetización visual que poder aplicar tanto en la creación como en la decodificación de mensajes visuales de todo tipo. Sin embargo, en las titulaciones que se imparten en la Facultad de Bellas Artes de la UCM, la competencia de la alfabetización visual no parece reflejada en los planes de estudio de casi ninguna de ellas, y si lo hace es de una forma implícita al hablar de lenguajes artísticos o cultura visual.

El análisis de los elementos de la imagen y su gramática solo aparece en dos asignaturas, una del Grado en Bellas Artes y otra del Grado en Diseño, por lo que consideramos importantes las prácticas planteadas desde el área de Formación Artística, ya que inducen a desarrollar el pensamiento visual, favoreciendo el procesamiento para convertir el conocimiento en imagen, transmitir información y potenciar el aprendizaje.

\section{Sobre la realización de las propuestas}

Hemos comprobado cómo, en general, no ha habido dificultades para realizar los ejercicios, salvo quizás entre el alumnado procedente de Historia del arte en el MEDART, por estar menos acostumbrados a la creación de imágenes.

A pesar de ello, podríamos decir que los pictogramas han cumplido más con la sencillez de ejecución que se les pedía, lo que puede deberse a la 
propuesta de la técnica utilizada, al contexto que se marcaba para su uso o a la propia naturaleza de la imagen, que posee menos elementos. Las metáforas, por las mismas razones, han sido más elaboradas, tanto visualmente como conceptualmente.

\section{Sobre el concepto arte representado}

Hemos visto cómo en las metáforas se amplía más el imaginario, utilizando más número y variedad de elementos a la hora de representar el concepto arte, incluyendo, por ejemplo, más disciplinas artísticas que no pertenecen a las artes plásticas y visuales, como la música, la danza o la literatura. Además, el concepto arte representado en las metáforas es más amplio que el representado en los pictogramas, quizás no tanto porque el estudiantado del MFPS tenga una visión menos compleja, completa o amplia del arte, sino porque la propuesta del pictograma para identificar espacios en una escuela de arte es más limitante que el de hacer una metáfora visual.

También, podríamos concluir que en las metáforas han transmitido más una idea propia de arte, con toda la complejidad y las implicaciones que quienes se están formando en ello pueden encontrar. Y en los pictogramas, al tener una premisa más de comunicación que de expresión y el propósito claro de transmitir una información más directa, se ha reflejado un concepto de arte más cercano al que puede tener el público general. 


\section{Referencias}

Aguilar, O. (2012). Enfocando la metáfora visual:ópticas cognitivas I. Culturales, 8(16), 33-84. http:// www.scielo.org.mx/scielo.php?script=sci_arttext\&pid=S1870-11912012000200002\&lng= es\&tlng=es

Aladro, E. (2007). Metáforas e iconos para transmitir información. CIC. Cuadernos de Información y Comunicación, 12, 49-57.

Amador-Baquiro, J. C. (2021). Memorias de hechos atroces, emprendimientos artístico-estéticos y visualidad: un estado de la cuestión. Encuentros, 19(01), 40-62.

Antúnez del Cerro, N. (2005). ¿Qué es el arte? Evolución del concepto de arte en los alumnos de la licenciatura de Bellas Artes. Arte, Individuo y Sociedad, 17, 155-174.

Antúnez del Cerro, N. (23 de octubre de 2014). Pictogramas. [Clase dentro de la asignatura Procesos y Métodos del Diseño de la especialidad de Artes Plásticas del Máster de Formación del Profesorado de la UCM]. Facultad de Bellas Artes, Universidad Complutense de Madrid.

Arnheim, R. (1969). El pensamiento visual. Paidós.

Cantón, J. (2017). Pensamiento visual para la creatividad y la narrativa mediante herramientas digitales. OpenCourseWare-UNIA (ocw.unia.es). https://dspace.unia.es/bitstream/ handle/10334/3762/01_Matbas_Tema1_PensamientoVisual.pdf?sequence=1\&isAllowed=y

Cuenca, M. J. y Hilferty, J. (1999). Introducción a la lingüística cognitiva. Ariel.

Cuevas, M. (s.f.). Ficha de Análisis de la forma. https://www.ucm.es/gradobellasartes/analisisde-la-forma

De Salazar-Muñoz, I. M. y Albar-Mansoa, P. J. (2016). El dibujo de contornos ciegos en el retrato gráfico: una propuesta metodológica en su enseñanza. Ardin. Arte, diseño e ingeniería, 5, 1-15.

Departamento de Estudios e Imagen Corporativa. (2021). Díptico del Grado en Diseño. Universidad Complutense de Madrid.

Eppler, M. J., \& Burkhard, R. A. (2007). Visual representations in knowledge management: framework and cases. Journal of Knowledge Management, 11(4), 112-122.

Facultad de Bellas Artes UCM. (s.f.). Competencias del Grado en Diseño. https://www.ucm.es/ gradodiseno/competencias 
Facultad de Bellas Artes UCM. (s.f.). Competencias del Máster Universitario en Investigación en Arte y Creación. https://www.ucm.es/master-en-investigacion-en-arte-y-creacion/ competencias

Facultad de Bellas Artes UCM. (s.f.). Estructura del Máster Universitario en Investigación en Arte y Creación. https://www.ucm.es/master-en-investigacion-en-arte-y-creacion/estructura-del-master

Facultad de Bellas Artes UCM. (s.f.). Estructura del plan de estudios del Grado en Diseño. https:// www.ucm.es/gradodiseno/estructura-del-plan-de-estudios

Ferruzca, M. V., Alceves, J. I. y Acosta I. (2015). Aproximaciones conceptuales para entender el diseño en el siglo XXI. Compilación. Universidad Autónoma Metropolitana.

Fuster, J. M. (1995). Memory in the Cerebral Cortex. The MIT Press.

Garcés, M. (2020). Nietzsche y la experiencia estética como "superabundancia de fuerzas comunicativas". Bajo Palabra, Revista de Filosofía, 24, 401-414.

Hall, S. (2007). Esto significa esto. Esto significa aquello. Semiótica: guía de los signos y su significado. Blume.

Hoffman, D. D. (1998). Visual Intelligence. How We Create What We See. W. W. Norton.

Kellner, D. (1998). Multiple literacies and critical pedagogy in a multicultural society. Educational Theory, 48(1), 103-122.

Kreger-Silverman, L. (2005). Upside-Down Brilliance: The Visual-Spatial Learning. http://pegy. org.uk/Upside-Down\%20Brilliance\%20-A4\%20pdf.pdf

Lakoff, G. (1993). The Contemporary Theory of Metaphor. In A. Ortony (Ed.), Metaphor and Thought. Cambridge University Press.

Lowenfeld, V. y Brittain, W.L. (1972). Desarrollo de la capacidad creadora. Editorial Kapelusz.

Magariños de Morentin, J. (2001). La(s) semiótica(s) de la imagen visual. Cuadernos de la Facultad de Humanidades y Ciencias Sociales, 17, 294-320.

Martín-Hernández, R. (2020). Prácticas artísticas contemporáneas y circulación de afectos. Relaciones entre imagen, experiencia, agencia y afectividad. Arte, Individuo y Sociedad, 32(3), 697-714. https://doi.org/10.5209/aris.65203

Martínez-Vérez, M. V. y Albar, P. J. (2019). Tinta de mar: Arte de acción en la formación profesional docente. Utopía y Praxis Latinoamericana, 87, 137-150. 
McCloud, S. (2008). Entender el cómic: El arte invisible. Astiberri.

Mirzoeff, N. (2003). Una introducción a la cultura visual. Paidós.

Nubiola, J. (2000). El valor cognitivo de las metáforas. En P. Pérez-Ilzarbe y R. Lázaro (Eds.), Verdad, bien y belleza. Cuando los filósofos hablan de los valores (pp. 73-84). Cuadernos de Anuario Filosófico n 103, Pamplona. https://pages.uoregon.edu/tpayne/Nubiola.pdf

Ojemann, N. (1987). Wat bewoog Nel Ojemann om haar leven zo in te zetten voor het kind met taal-/lees- problematiek? http://www.ojemann.nl/nelojemann.html

Ortiz, M. J. (2011). La Metáfora Visual Corporeizada: Bases Cognitivas del Discurso Audiovisual. Zer. Revista de Estudios de Comunicación, 16(30), 57-73.

pensamientovisual.es. (s.f.). Tipos de signos gráficos: icono, indicio, símbolo, pictograma, ideograma y otros. https://www.pensamientovisual.es/tipos-signos-graficos

Sonesson, G. (1994). Prolegomena to a semiotic analysis of prehistoric visual displays. Semiotica, 100(3), 267-332.

Sonesson, G. (1997). Semiotics around the World: Synthesis in Diversity. In Rauch, Irmengard, \& Carr, Gerlard F. (Eds.), Proceedings of the Fifth International Congress of the IASS, Berkeley, June 12-18, 1994 (pp. 739-742). Mouton de Gruyter, Berlin \& New York.

Spencer, C., Blades, M., \& Morsley, K. (1989). The child in the physical environment: The development of spatial knowledge and cognition. Wiley.

Stokes, S. (2002). Visual Literacy in Teaching and Learning: A Literature Perspective. Electronic Journal for the Integration of Technology in Education, 1(1), 10-19.

Worren, N. A., Moore, K., \& Elliott, R. (2002). When theories become tools: toward a framework for pragmatic validity. Human Relations, 55(10), 1227-1250.

Zurdo, L. (s.f.). Ficha de Análisis de la forma. https://www.ucm.es/gradodiseno/elementos-dela-plastica

Cómo citar: Albar, P. J. y Antúnez del Cerro, N. (2022). Alfabetización visual de docentes de arte en formación en la Facultad de Bellas Artes (UCM) a través de representaciones visuales de su propio concepto de arte. Revista KEPES, 19(25), 191-221. https://doi.org/10.17151/kepes.2022.19.25.8 